\title{
Desigualdades intraurbanas e a Covid-19: uma análise do isolamento social no município de Porto Alegre
}

\author{
Intra-urban inequalities and Covid-19: \\ an analysis of social isolation in the city of Porto Alegre
}

André Coutinho Augustin [I] Paulo Roberto Rodrigues Soares [II]

\begin{abstract}
Resumo
A pandemia de Covid-19 explicitou desigualdades territoriais já presentes nas cidades brasileiras. Uma das formas de expressão dessas desigualdades foi a possibilidade de ficar em casa para se prevenir. Analisando um índice de isolamento social calculado a partir de dados de localização de telefones celulares, este artigo mostra que $o$ isolamento no município de Porto Alegre não aconteceu de forma homogênea no território. Fatores como a ocupação, a renda e o IDH de cada região da cidade se relacionam com as diferentes taxas de isolamento encontradas e, consequentemente, ajudam a entender os diferentes graus de exposição ao vírus.

Palavras-chave: Covid-19; coronavírus; pandemia; isolamento social; Porto Alegre.
\end{abstract}

\begin{abstract}
The Covid-19 pandemic has revealed territorial inequalities that were already present in Brazilian cities. One way in which these inequalities were expressed was the possibility of staying at home as a form of prevention. Analyzing a social isolation index based on cell phone location data, this paper shows that isolation in the city of Porto Alegre did not happen homogeneously in the territory. Factors such as occupation, income and the HDI for each region of the city are related to the different isolation rates that were found and, consequently, help us to understand the different degrees of exposure to the virus.
\end{abstract}

Keywords: Covid-19; coronavirus; pandemic; social isolation; Porto Alegre. 


\section{Introdução}

No ano de 2020, o mundo foi marcado pelo início da maior pandemia em décadas, a pandemia do Sars-COV-2, ou de Covid-19. Essa também pode ser considerada a primeira epidemia mundial acompanhada em "tempo real" na era da Internet. Iniciada na metrópole industrial de Wuhan, na República Popular da China, a pandemia espalhou-se rapidamente por todos os continentes. Somente nos primeiros seis meses de 2020, cerca de 500 mil pessoas haviam morrido no mundo, vítimas do novo coronavírus, número que já havia dobrado em setembro (Johns Hopkins University, 2020). No Brasil, a primeira confirmação de Covid-19 ocorreu, em 26 de fevereiro, em um morador de São Paulo que havia voltado de uma viagem para a Itália. Em 31 de dezembro, já eram 7,6 milhões de casos e mais de 197 mil óbitos confirmados (Brasil, 2020).

A pandemia gerou uma série de impactos econômicos, sociais e, até mesmo, políticos e culturais em todo o mundo. A economia mundial sofreu uma grave retração, houve o crescimento do desemprego, cidades tiveram suas rotinas completamente alteradas por medidas de isolamento social e lockdowns. Como vivemos em uma sociedade desigual, a pandemia também "distribuiu" desigualmente seus efeitos entre os diferentes países, territórios e classes sociais. É sobre uma dessas desigualdades a que vamos nos referir.

No caso brasileiro, a pandemia explicitou a desigualdade no acesso à saúde, situação histórica agravada nos últimos anos pelos sucessivos cortes de orçamento. Apenas em 2019, a Emenda Constitucional 95 (conhecida como "emenda do teto dos gastos") causou uma redução de $\mathrm{R} \$ 20$ bilhões nos investimentos federais em saúde, fazendo com que o orçamento da área fosse de $\mathrm{R} \$ 122,6$ bilhões (CNS, 2020). Já os planos privados de saúde, com cerca de 70 milhões de clientes, tiveram receitas de $\mathrm{R} \$ 226$ bilhões no mesmo ano (ANS, 2020). É importante ressaltar que a saúde pública atende aos 211 milhões de brasileiros, pois, mesmos aqueles que possuem planos de saúde, acabam usando o SUS para atendimentos não cobertos pelos planos, principalmente na atenção de alta complexidade (a mais cara), além de campanhas de vacinação e de outros serviços que muitas vezes a população nem percebe que faz parte do orçamento da saúde, como o trabalho de fiscalização da vigilância sanitária.

Essa brutal diferença no financiamento, com a saúde pública tendo que oferecer mais serviços que a privada com menos recursos, reflete uma desigualdade social mais profunda. Segundo a Organização das Nações Unidas, o Brasil é o segundo país do mundo com maior concentração de renda, com $1 \%$ da população recebendo $28,3 \%$ da renda (UNDP, 2019, p. 309). O patrimônio é ainda mais concentrado, com apenas $0,1 \%$ da população tendo a propriedade de $30 \%$ dos bens e direitos líquidos declarados (Unafisco, 2020). Apesar disso, uma parcela significativa da saúde privada não é paga por essa renda dos mais ricos, mas por recursos públicos, através de mecanismos como a dedução de despesas médicas no Imposto de Renda Pessoa Física, que, em 2017, foi responsável por uma renúncia fiscal de $\mathrm{R} \$ 15,1$ bilhões (86\% dos quais apropriados pelos $10 \%$ mais ricos). Nesse mesmo ano, o total de subsídios federais para a saúde privada foi de $\mathrm{R} \$ 45,9$ bilhões, representando $40 \%$ do gasto direto em saúde no País (Brasil, 2019). 
Mas o acesso ao atendimento é apenas uma das expressões de desigualdade na saúde. Há inúmeras outras, como as diferentes formas de exposição a riscos no trabalho e a falta de acesso ao saneamento básico e a uma alimentação saudável, por exemplo. A pandemia de Covid-19 acrescentou mais uma forma de desigualdade: a do direito ao distanciamento social.

Há diversos estudos mostrando a importância do distanciamento para o controle da disseminação do vírus. Hsiang et al. (2020) mostram que medidas como o fechamento de escolas e restrições à circulação na China, Coreia do Sul, Itália, Irã, França e Estados Unidos preveniram ou atrasaram 61 milhões de casos confirmados, o que corresponde a aproximadamente 495 milhões de infecções totais. Aquino et al. (2020, p. 2430), após a triagem de 2.771 artigos sobre a Covid-19 publicados no PubMed e análise de 21 destes, concluem que "há fortes indicações de que as estratégias de controle da expansão da epidemia são efetivas quando o isolamento de casos e a quarentena dos contatos são combinados com um conjunto de medidas de distanciamento social que abranja toda a população". Zhou et al. (2020), num estudo com dados de localização de telefones na cidade de Shenzhen, na província chinesa de Guangdong, estimam que uma restrição de $20 \%$ na mobilidade pode achatar o pico de casos em $33 \%$. Esse achatamento é ampliado para $66 \%$ com $40 \%$ de restrição e para $91 \%$ numa restrição de $60 \%$ da mobilidade. Gao et al. (2020), analisando a localização de 45 milhões de telefones celulares nos Estados Unidos, apontam que o distanciamento social está associado à redução nas taxas de Covid-19. Num estudo para as capitais brasileiras, Marino, Komatsu e Menezes-Filho (2020) compararam decretos de distanciamento estaduais e municipais, índices de isolamento calculados a partir da localização de dispositivos móveis e casos de Covid-19. Os autores concluíram que, apesar de o isolamento seguir uma mesma tendência geral em todo o País, medidas locais têm efeitos significativos no aumento do isolamento e na redução do contágio.

A despeito da importância do distanciamento na prevenção da pandemia, em nosso País nem todos tiveram esse direito. A pesquisa Pnad Covid, do IBGE, mostra que só entre os trabalhadores com ensino superior completo, o trabalho remoto (home office) é uma realidade e, mesmo assim, para menos da metade deles. Entre os trabalhadores com ensino fundamental completo, apenas $1 \%$ estava trabaIhando remotamente em setembro de 2020, valor que se reduz para $0,4 \%$ entre os trabaIhadores sem instrução ou com fundamental incompleto. Em relação à raça, o trabalho remoto era realizado por $14,3 \%$ dos brancos e por $6,8 \%$ dos pretos e pardos.

Esses números indicam que as diferentes formas de inserção no mercado de trabalho podem ajudar a entender a dinâmica do distanciamento social e do contágio pelo coronavírus, que não se dá de forma homogênea socialmente nem territorialmente. No entanto, são poucos os estudos que mostram essas relações. A maioria das pesquisas brasileiras sobre distanciamento social e seus efeitos na pandemia apresenta resultados agregados para estados ou municípios, o que é explicado principalmente pela falta de dados.

Por um lado, os dados sobre casos e óbitos são insuficientes. Além da subnotificação, não há divulgação completa das informações disponíveis. Ainda em maio, o Ministério da 
Tabela 1 - Percentual de pessoas ocupadas e não afastadas do trabalho que trabalhavam de forma remota, por nível de instrução

\begin{tabular}{l|c|c|c|c|c}
\hline & Maio & Junho & Julho & Agosto & Setembro \\
\hline Sem instrução ao fundamental incompleto & 0,6 & 0,4 & 0,5 & 0,5 & 0,4 \\
\hline Fundamental completo ao médio incompleto & 1,7 & 1,4 & 1,3 & 1,2 & 1,0 \\
\hline Médio completo ao superior incompleto & 7,9 & 7,3 & 6,7 & 6,0 & 5,4 \\
\hline Superior completo ou pós-graduação & 38,3 & 37,3 & 35,0 & 33,6 & 32,3 \\
\hline Total & 13,3 & 12,7 & 11,7 & 11,1 & 10,4 \\
\hline
\end{tabular}

Fonte: IBGE (2020).

Saúde retirou o CEP da planilha pública sobre internações por Síndrome Respiratória Aguda Grave - SRAG (Marino et al., 2020a). Isso impediu a realização de mais pesquisas como aquela realizada pelo Laboratório Espaço Público e Direito à Cidade (LabCidade), da USP, que mostrou a importância da análise territorial da pandemia. Cruzando a base de dados de internações por SRAG com a Pesquisa Origem Destino e com dados de GPS dos ônibus de São Paulo, mostrou-se uma forte associação dos locais de residência dos pacientes internados por SRAG com as áreas que concentram mais origens de viagens de pessoas sem ensino superior e em cargos não executivos, os quais usam o transporte público como principal modal para deslocamentos por trabalho (Marino et al., 2020b). Não existindo mais a disponibilidade de uma base de dados nacional, estudos como este dependem da divulgação de informações por parte dos governos locais, o que nem sempre acontece.

Por outro lado, também faltam informações sobre o distanciamento. A principal fonte de dados sobre isso tem sido a localização de aparelhos de telefonia móvel. No Brasil, o indicador mais utilizado é o Índice de Isolamento Social desenvolvido pela empresa Inloco a partir de dados de 60 milhões de aparelhos. No entanto, a Inloco só divulga publicamente o índice para o País e para as unidades da federação. As poucas pesquisas em nível municipal são resultado de convênios da empresa com governos locais ou pesquisadores. Um exemplo é o estudo desenvolvido por Natividade et al. (2020), que mostrou que os bairros de Salvador com maiores indicadores de pobreza possuem um índice de isolamento menor.

Partindo dessa ampla discussão, este artigo pretende analisar o Índice de Isolamento Social durante a pandemia de Covid-19 para as diferentes regiões do município de Porto Alegre. ${ }^{1}$ Para isso foram usados dados cedidos pela Inloco para o Comitê de Dados do Gabinete de Crise para o Enfrentamento da Epidemia Covid-19 do estado de Rio Grande do Sul, do qual um dos autores deste artigo faz parte. Inicialmente serão feitas algumas considerações sobre as desigualdades territoriais em Porto Alegre. Depois serão apresentados os dados 
de isolamento para as diferentes áreas da cidade, cruzando com as tipologias socioespaciais do Observatório das Metrópoles, com a renda média e com o IDH.

\section{Desigualdades territoriais em Porto Alegre}

Há evidências de que a desigualdade econômica influencia o risco de infecção e morte por Covid-19 (Demenech et al., 2020), algo relevante para um país como o Brasil. Apesar do senso comum de cidade do sul do Brasil, região tida com menores desigualdades sociais do País, Porto Alegre é uma metrópole muito desigual. Seu território apresenta setores com elevados indicadores socioeconômicos e considerável qualidade, bem como amplas periferias urbanas com diversos problemas sociais e ambientais.

Os dados do Índice de Desenvolvimento Humano Municipal (IDH-M), apresentados no Atlas Brasil (Pnud, FPJ, Ipea, 2020), por exemplo, apontam diferenças marcantes entre as áreas mais ricas (Moinhos de Vento, Chácara das Pedras, Jardim Isabel, com um IDH-M de 0,958 ) e as mais pobres da cidade (Sarandi, Humaitá, Restinga, com IDH-M de 0,593). As primeiras com indicadores "de primeiro mundo" e as últimas comparáveis a alguns dos países mais pobres do planeta. Essas desigualdades se manifestam na infraestrutura urbana, na qualidade ambiental dos espaços, na disponibilidade e qualidade dos serviços (incluindo os serviços de saúde), na acessibilidade e na mobilidade, o que se configura em termos de oportunidades de educação e trabalho refletindo na expectativa de vida dos habitantes, como apontam os dados do IDH-M Longevidade: os setores mais bem colocados (Bela Vista, Moinhos de Vento, Menino Deus) têm um índice de 0,952, enquanto os piores (Restinga, Mario Quintana, Vila Dique) estão na faixa de 0,763. Os dados do Índice de Bem-estar Urbano (Ibeu) do Observatório das Metrópoles (Ribeiro e Ribeiro, 2016) confirmam essa desigualdade intraurbana no município de Porto Alegre, com o indicador variando de 0,967 na área mais bem situada e 0,656 no setor menos favorecido.

Na Região Metropolitana de Porto Alegre (RMPA), as evidências das desigualdades são semelhantes. Enquanto o município de Porto Alegre apresenta os melhores índices (IDH-M de 0,805), municípios periféricos apresentam índices bem mais baixos, como São Jerônimo $(0,696)$, Alvorada $(0,699)$ e Viamão $(0,717)$. No caso do Ibeu, este varia de 0,967 no melhor setor (em Porto Alegre) a 0,615 no mais mal situado (no município de Viamão). Note-se que os dez melhores setores do Ibeu se localizam em Porto Alegre, enquanto os dez piores se situam em Alvorada, Viamão, Gravataí e Canoas, todos municípios limítrofes a Porto Alegre, sendo Alvorada e Viamão configurados como extensões da mancha urbana periférica da capital.

Essa distribuição no território de indicadores sociais também se relaciona com o trabalho, já que, como disse Santos (2012, pp. 120-121), "a divisão do trabalho [...] é uma das chaves para a explicação da distribuição, sobre a Terra, dos homens e das atividades". Uma forma de observar isso é a partir das tipologias socioespaciais desenvolvidas pelo Observatório das Metrópoles (Mammarella et al., 2015). Utilizando dados do Censo Demográfico de 2010, principalmente da ocupação 
profissional, a população é classificada em 24 categorias sócio-ocupacionais. Já os territórios são divididos em tipologias socioespaciais, dependendo da concentração de cada uma das categorias. A Figura 1 mostra a distribuição das tipologias na RMPA. São cinco classificações (superiores, médios, operários, populares e agrícolas), e o município de Porto Alegre possui apenas três delas.

Nota-se que, em Porto Alegre, há um grande predomínio dos grupos considerados médios, bem como há forte presença dos grupos superiores, que abarcam quase a totalidade desses setores na região metropolitana. Os setores considerados populares ocupam a ampla faixa periférica do município, transbordando-se para as cidades limítrofes de Alvorada, Viamão, Canoas, Eldorado do Sul e Guaíba.

Essas desigualdades se refletem nos diferentes comportamentos sociais e impactos socioeconômicos que a pandemia da Covid-19 gerou no município de Porto Alegre e na sua Região Metropolitana, como veremos a seguir.

Figura 1 - Tipologias socioespaciais na Região Metropolitana de Porto Alegre - 2010

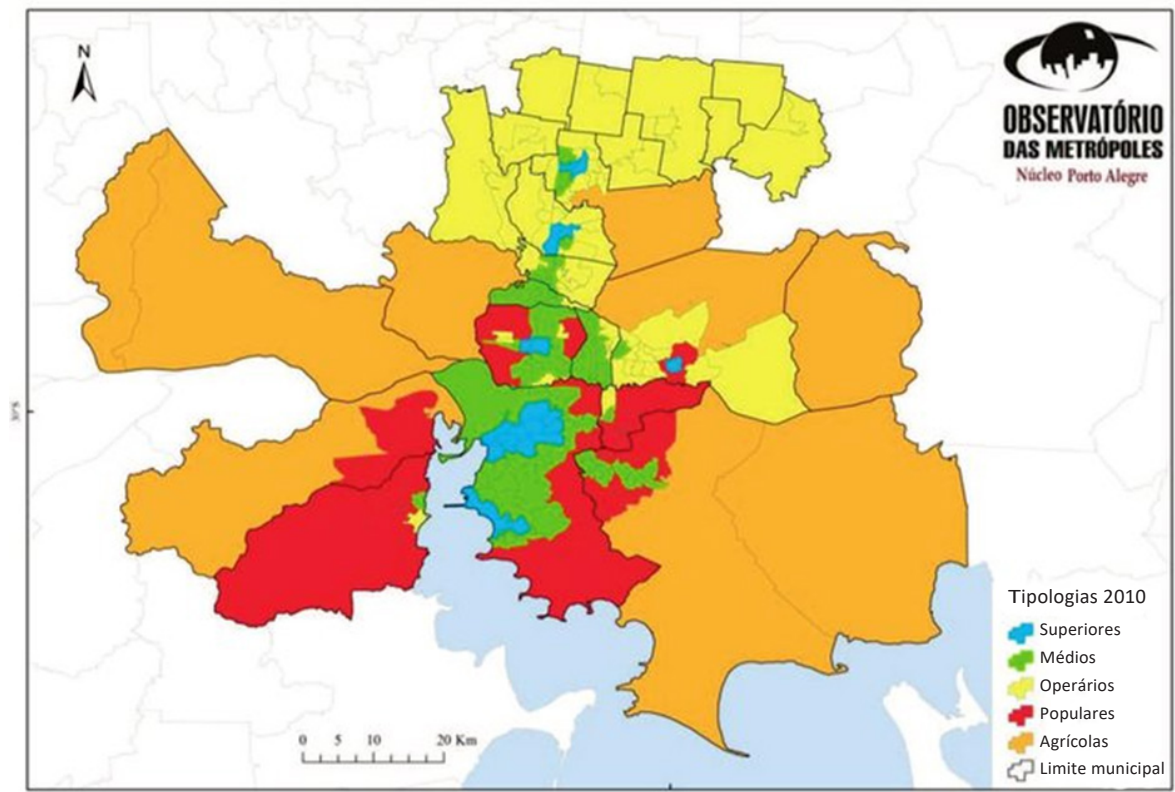

Fonte: Mammarella et al. (2015, p. 173). 


\section{Índice de isolamento social em Porto Alegre durante a pandemia de Covid-19}

A análise da circulação de pessoas em Porto Alegre durante a pandemia será feita utilizando o índice de isolamento social criado pela Inloco. Através de aplicativos parceiros, a empresa possui acesso à localização de dispositivos móveis de 60 milhões de usuários em todo o Brasil, 540 mil dos quais em Porto Alegre. 0 cálculo do índice não identifica esses usuários, garantindo a privacidade e o anonimato.

Para medir o isolamento, a Inloco divide o espaço em hexágonos de cerca de 450 metros de raio. É considerada, em isolamento, aquela pessoa que permaneceu todo o dia no mesmo hexágono. Já quem muda sua localização para outro polígono pelo menos uma vez no dia é considerado fora de isolamento, sendo contabilizado na área onde estava durante a noite, onde se supõe ficar sua residência.

Em todo o Brasil, a tendência de isolamento foi semelhante, com um pico no fim de março e uma queda gradual desde então. No entanto, o pico de Porto Alegre (62\% na média de sete dias) foi superior ao brasileiro (54\%). A diferença, que estava sendo reduzida, voltou a aumentar no final de junho, quando o frio e a chuva típicos do inverno gaúcho fizeram o isolamento aumentar em todo o estado (Rio Grande do Sul, 2020a).

$\mathrm{O}$ isolamento médio de cada cidade, entretanto, esconde grandes diferenças intraurbanas, tornando relevante a análise do índice para cada região da cidade. Para isso, é necessário olhar os dados por polígono de cálculo do

Gráfico 1 - Índice de isolamento social em Porto Alegre e no Brasil

$(1 / 3 / 2020$ a $24 / 10 / 2020)$

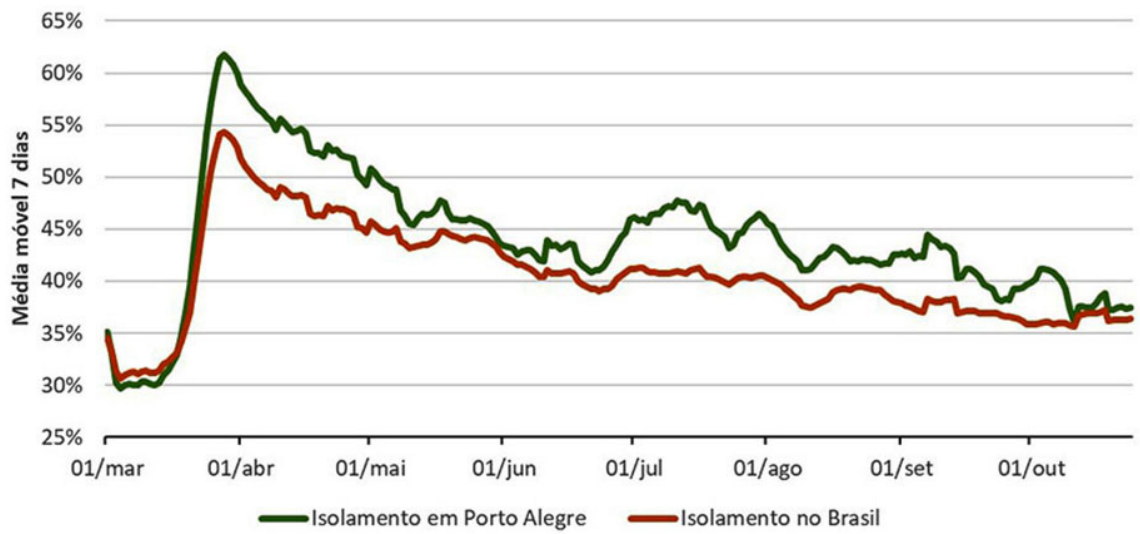

Fonte: Inloco (2020). 
Figura 2 - Índice de isolamento social em Porto Alegre

(valor médio entre $7 / 6$ e 24/10/2020)

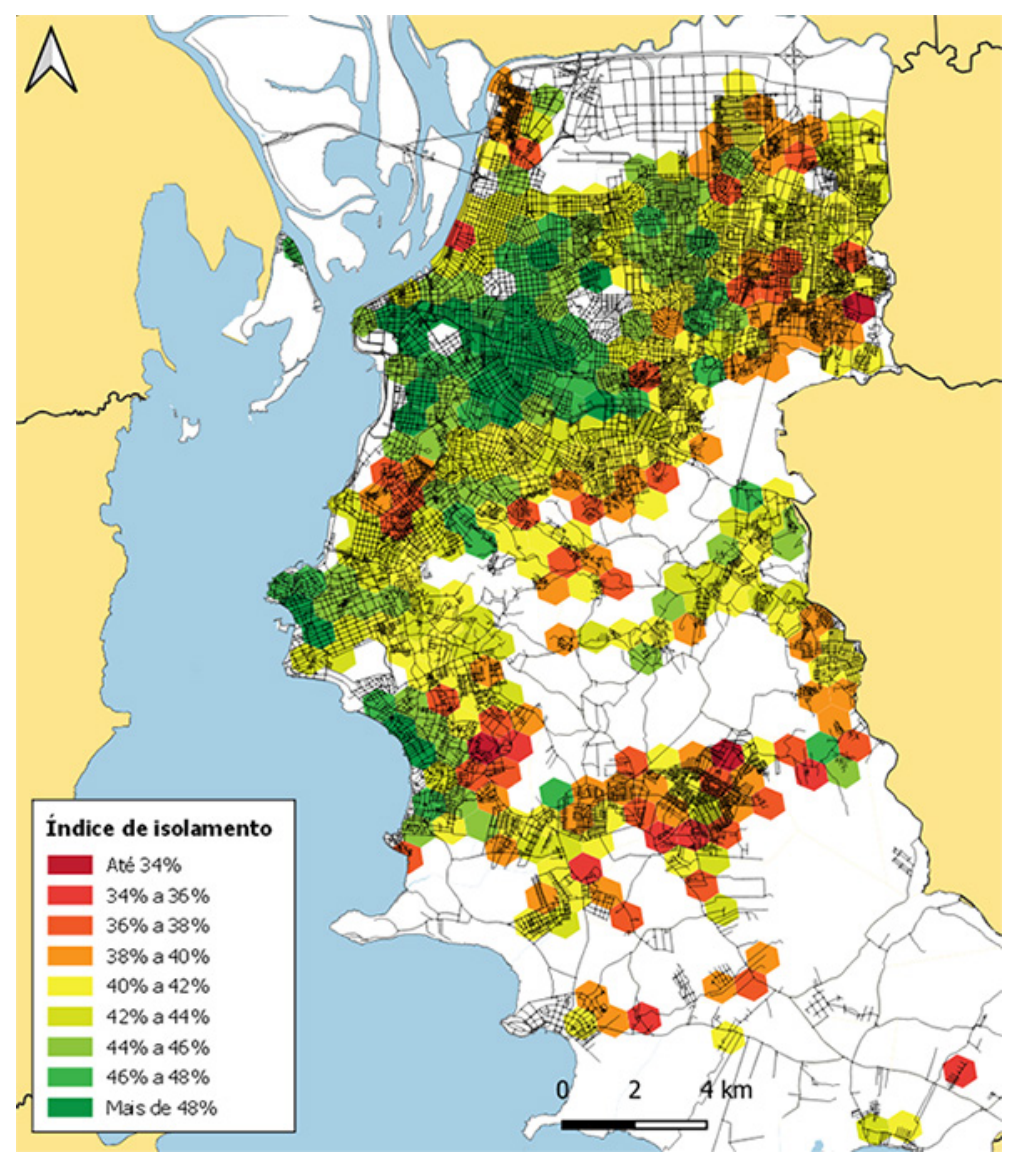

Fonte dos dados brutos: Inloco (2020).

índice. Ao contrário do isolamento municipal, as informações por polígono não estavam disponíveis para toda a série, motivo pelo qual o estudo foi feito apenas para o período de 7 de junho a 24 de outubro de 2020. ${ }^{2}$

Além disso, só foram considerados os locais onde havia dados para todo o período de análise. Como é necessário um número mínimo de telefones conectados ${ }^{3}$ para calcular o índice de isolamento de cada polígono no dia, alguns deles não aparecem sempre na base. Dos 421 polígonos da cidade de Porto Alegre,
341 tinham o índice para todos os 139 dias analisados. Na Figura 2 é mostrado o valor médio do Índice de isolamento social em cada um desses 341 hexágonos.

Para quem conhece Porto Alegre, visualmente o mapa já deixa claro, por um lado, que os maiores níveis de isolamento acontecem nos bairros centrais e em alguns trechos da orla do Guaíba na zona Sul, justamente as áreas mais ricas da cidade. Por outro lado, as regiões de menor renda possuem índices mais baixos de isolamento. 
Para explorar melhor essas diferenças espaciais, serão apresentados os cruzamentos do índice de isolamento social com três variáveis, cada uma delas na escala para a qual está disponível:

1) Tipologias socioespaciais, nas áreas de ponderação do Censo;

2) Renda, nos setores censitários;

3) IDH, nas regiões do Orçamento Participativo.

Nos três casos, a fonte dos dados é o Censo de 2010 que, embora desatualizado, é a única base disponível nesse nível de desagregação. ${ }^{4}$

\section{Índice de isolamento social e tipologias socioespaciais}

As tipologias socioespaciais do Observatório das Metrópoles, já apresentadas, são definidas a partir das variáveis do questionário da amostra do Censo, mais amplo que o questionário geral. Por isso, só podem ser calculadas por área de ponderação, já que o setor censitário, menor área, não tem dados da amostra divulgados pelo IBGE.
O território de Porto Alegre é dividido em três tipologias: populares, médios e superiores. Para calcular o índice de isolamento de cada uma delas, foi feita uma média de todos os polígonos da Inloco que estão no interior das áreas de ponderação classificadas naquela tipologia. No caso dos polígonos localizados na divisa entre duas tipologias, o valor dos seus índices entrou no cálculo da média ponderada pela área da intersecção com cada uma delas.

Como esperado, as áreas com a tipologia "Superiores" tiveram o maior isolamento, $(45,3 \%)$ e "Populares", o menor (40,2\%). A diferença é maior nos dias úteis, o que sugere uma relação do trabalho com o nível de isolamento. Outros fatores influenciam de forma semelhante as diferentes regiões. Nos dias de chuva, ${ }^{5}$ por exemplo, o isolamento aumentou, em média, 5,4 pontos percentuais na tipologia "populares", 5,1 na "médios" e 5,3 na "superiores".

Durante o período analisado, julho foi o mês que apresentou maior isolamento em todas as tipologias, o que pode ser explicado tanto pelo alto número de dias chuvosos

Quadro 1 - Isolamento médio por tipologia socioespacial $7 / 6$ a $24 / 10 / 2020$

\begin{tabular}{|l|c|c|c|c|}
\hline & $\begin{array}{c}\text { Dias úteis } \\
\%\end{array}$ & $\begin{array}{c}\text { Sábados } \\
\%\end{array}$ & $\begin{array}{c}\text { Domingos e feriados } \\
\%\end{array}$ & $\begin{array}{c}\text { Total } \\
\%\end{array}$ \\
\hline Populares & 36,9 & 42,1 & 52,1 & 40,2 \\
\hline Médios & 38,0 & 43,2 & 53,1 & 41,3 \\
\hline Superiores & 42,4 & 47,0 & 56,1 & 45,3 \\
\hline
\end{tabular}

Fonte dos dados brutos: Inloco (2020). 
quanto pelas maiores restrições legais ao funcionamento de diversos setores da economia. Esse também foi o mês em que a diferença de isolamento entre as tipologias foi maior para os fins de semana. Já, nos dias úteis, a maior diferença foi encontrada em agosto, quando mudanças no decreto estadual que estabelecia o "distanciamento controlado" permitiram a abertura do comércio, o que indica que a volta ao trabalho ocorrida nesse período atingiu de forma diferente cada parcela da população.

Embora esses dados demonstrem uma desigualdade no isolamento entre as regiões de cada tipologia, a diferença não é muito grande. Isso ocorre provavelmente devido à escala de cálculo. As áreas de ponderação do Censo, de acordo com as quais as tipologias são classificadas, abrangem espaços heterogêneos. A Figura 3 mostra uma parte da cidade na qual estão presentes apenas áreas classificadas com as tipologias Superiores e Médios.
Junto com o isolamento de cada hexágono, foi incluído um mapeamento de áreas com irregularidades fundiárias, realizado pelo Departamento Municipal de Habitação (Demhab). São justamente essas áreas mais pobres (como as vilas do morro Santa Teresa e da Bom Jesus) que representam os pontos de baixo isolamento dentro das regiões de isolamento mais alto. Se possuíssem uma classificação própria de tipologia, essas vilas provavelmente seriam consideradas Populares, mas o nível de agregação de divulgação dos dados do Censo acaba juntando-as com áreas com características sociais muito diferentes.

A alternativa para evitar esse problema é usar dados por setor censitário, a menor área do Censo. No entanto, nem todas as variáveis são divulgadas pelo IBGE para esse nível de desagregação. Ao invés das tipologias socioespaciais, que sintetizam diversas variáveis, para os setores censitários, a análise considerou apenas a renda.

Tabela 2 - Isolamento médio mensal por tipologia socioespacial $7 / 6$ a $24 / 10 / 2020$

\begin{tabular}{l|l|c|c|c|c|c}
\hline \multicolumn{2}{l|}{} & $\begin{array}{c}\text { Junho } \\
\%\end{array}$ & $\begin{array}{c}\text { Julho } \\
\%\end{array}$ & $\begin{array}{c}\text { Agosto } \\
\%\end{array}$ & $\begin{array}{c}\text { Setembro } \\
\%\end{array}$ & \multicolumn{2}{c}{$\begin{array}{c}\text { Outubro } \\
\%\end{array}$} \\
\hline \multirow{3}{*}{\begin{tabular}{l} 
Dias úteis \\
\cline { 2 - 7 }
\end{tabular}} & Populares & 37,7 & 40,7 & 37,1 & 34,9 & 33,0 \\
\cline { 2 - 7 } & Médios & 39,0 & 42,1 & 38,5 & 35,7 & 33,7 \\
\cline { 2 - 7 } & Superiores & 43,4 & 46,7 & 43,2 & 39,8 & 37,5 \\
\hline \multirow{2}{*}{$\begin{array}{l}\text { Sábados, } \\
\text { domingos e } \\
\text { feriados }\end{array}$} & Populares & 48,1 & 49,9 & 47,2 & 47,9 & 44,1 \\
\cline { 2 - 7 } & Médios & 49,7 & 51,6 & 48,0 & 48,9 & 44,2 \\
\cline { 2 - 7 } & Superiores & 53,3 & 55,7 & 51,5 & 51,9 & 47,1 \\
\hline \multirow{2}{*}{\begin{tabular}{l} 
Total \\
\cline { 2 - 7 }
\end{tabular}} & Populares & 41,4 & 43,1 & 40,3 & 38,8 & 36,7 \\
\cline { 2 - 7 } & Médios & 42,7 & 44,5 & 41,6 & 39,7 & 37,2 \\
\hline
\end{tabular}

Fonte dos dados brutos: Inloco (2020). 
Figura 3 - Presença de vilas e índice de isolamento social

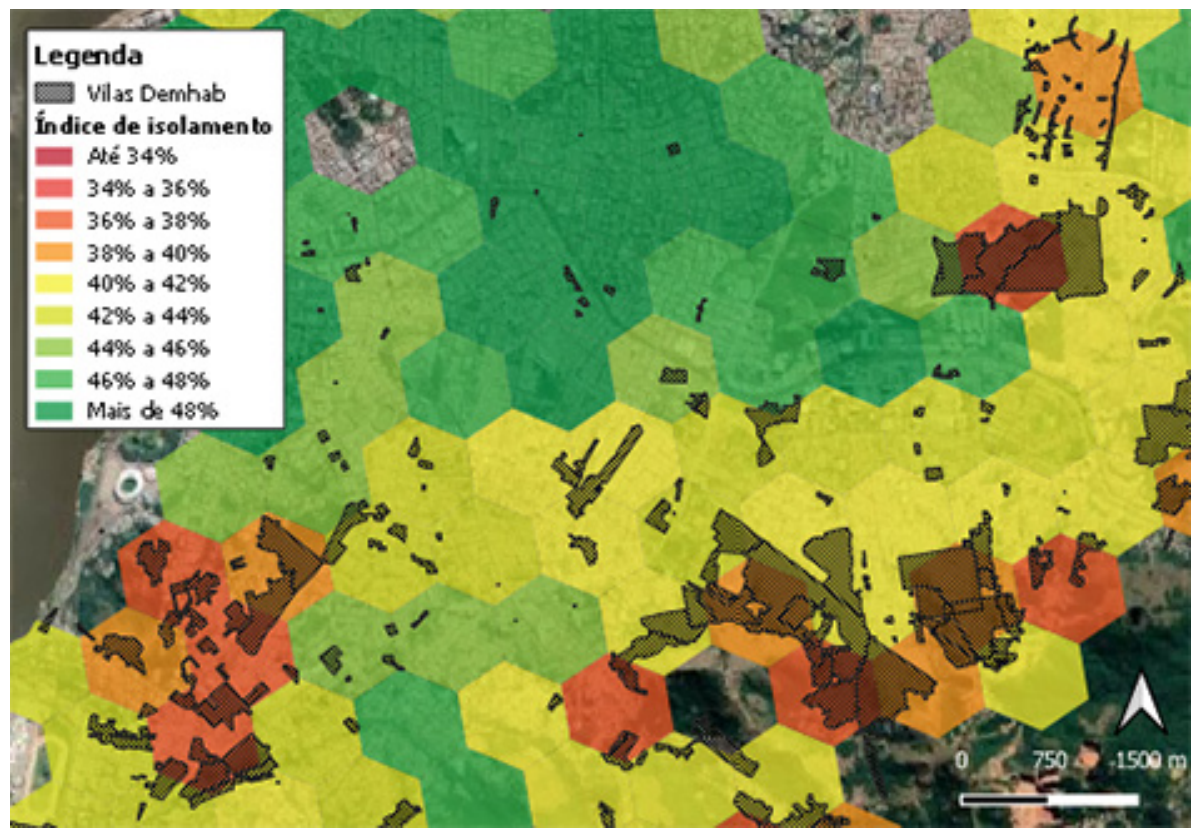

Fonte dos dados brutos: Inloco (2020). Mapa das vilas: ObservaPOA (2017). Imagem de fundo: Google Satellite.

Índice de isolamento social e setores censitários por faixa de renda

Para o cálculo do isolamento por setor censitário, os setores foram agregados por faixas de renda per capita, calculadas a partir da variável "valor do rendimento nominal médio mensal das pessoas de 10 anos ou mais de idade (com e sem rendimento)". Foram definidas seis faixas, de acordo com o valor do salário-mínimo vigente no ano de realização do Censo. Os resultados são apresentados na Tabela 3.
0 índice de isolamento social cresce à medida que a renda média do setor censitário aumenta. Um fato curioso é a diferença entre as duas maiores faixas. Nos dias úteis, o isolamento delas é quase igual, o que indica que, a partir de 5 salários-mínimos, um aumento de renda já não diferencia mais aqueles que podem trabaIhar em casa. Já, nos fins de semana, o isolamento das áreas de renda acima de 10 salários-mínimos apresenta um índice menor. Ou seja, entre os mais ricos a probabilidade de sair de casa para trabalhar é menor, mas, para passear, é maior. 
Tabela 3 - Isolamento médio mensal por faixa de renda dos setores censitários $7 / 6$ a $24 / 10 / 2020$

\begin{tabular}{l|c|c|c|c}
\hline & $\begin{array}{c}\text { Dias úteis } \\
\%\end{array}$ & $\begin{array}{c}\text { Sábados } \\
\%\end{array}$ & $\begin{array}{c}\text { Domingos e feriados } \\
\%\end{array}$ & $\begin{array}{c}\text { Total } \\
\%\end{array}$ \\
\hline Até 1 SM & 36,5 & 41,5 & 51,5 & 39,7 \\
\hline Mais de 1 a 2 SM & 37,1 & 42,4 & 52,4 & 40,4 \\
\hline Mais de 2 a 3 SM & 39,2 & 44,3 & 54,0 & 42,4 \\
\hline Mais de 3 a 5 SM & 41,5 & 46,4 & 55,9 & 44,6 \\
\hline Mais de 5 a 10 SM & 43,3 & 47,8 & 56,8 & 46,1 \\
\hline Mais de 10 SM & 43,4 & 46,7 & 55,4 & 45,9 \\
\hline
\end{tabular}

Fonte dos dados brutos: Inloco (2020) e IBGE (2011).

Considerando todo o período analisado, o isolamento médio dos setores com renda de 5 a 10 salários-mínimos foi 6,4 pontos percentuais maior que daqueles de renda até meio salário. A distância é maior do que a encontrada entre as três tipologias socioespaciais, mas, mais uma vez, um problema de escala pode ter subestimado essas diferenças. Os setores censitários representam uma área pequena e, logo, tendem a ser mais homogêneos que as áreas de ponderação. No entanto, a medida do isolamento continua sendo feita por hexágonos que possuem cerca de $630 \mathrm{mil} \mathrm{m2}$. A Figura 4 exemplifica o problema com um polígono de isolamento localizado na divisa dos bairros Chácara das Pedras, Jardim Europa e Vila Jardim. Ele possui setores censitários em todas as seis faixas de renda. Para calcular o isolamento médio de cada faixa, todos os setores dentro dele foram considerados como se tivessem o isolamento $41 \%$, a média do hexágono. Entretanto, cada pequena área dessa deve ter tido um isolamento real diferente.
Para resolver esse problema, que se repete em diversas regiões da cidade, foi criado um modelo que considera que cada faixa de renda possui uma taxa de média isolamento (desconhecida), e que o índice (conhecido) de cada polígono pode ser visto como uma combinação linear dessas taxas, ponderadas pela área que os setores censitários de cada faixa de renda per capita ocupa dentro do polígono. Para isso, foi realizada uma regressão linear múltipla em que o isolamento médio do período analisado de cada um dos 341 hexágonos é explicado pelo percentual de sua área coberto por setores censitários de cada uma das faixas de renda mais um erro. Para testar o efeito da localização, também foi incluída na regressão uma variável que mede a distância euclidiana medida em quilômetros - do centroide de cada hexágono até a prefeitura de Porto Alegre, localizada no Centro Histórico.

Todas as variáveis foram significativas ao nível de $1 \%$, e o resultado pode ser interpretado da seguinte forma: a interseção representa 
Figura 4 - Exemplo de setores censitários por renda e polígono de isolamento

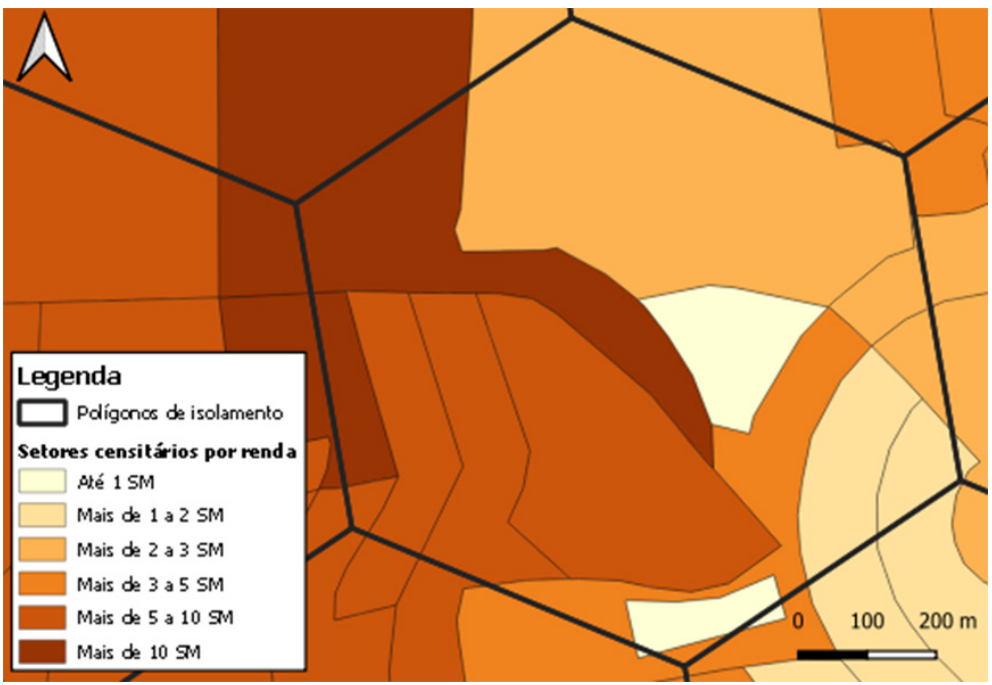

Fonte dos dados brutos: IBGE (2011).

Quadro 2 - Resultado da regressão

\begin{tabular}{|l|c|c|}
\hline & Coeficientes & valor-P \\
\hline Interseção & 0,3909 & 0,0000 \\
\hline Mais de 1 a 2 SM & 0,0255 & 0,0015 \\
\hline Mais de 2 a 3 SM & 0,0376 & 0,0000 \\
\hline Mais de 3 a 5 SM & 0,0781 & 0,0000 \\
\hline Mais de 5 a 10 SM & 0,0959 & 0,0000 \\
\hline Mais de 10 SM & 0,0559 & 0,0079 \\
\hline Distância Prefeitura & $-0,0012$ & 0,0011 \\
\hline R-Quadrado & 0,5427 & \\
\hline R-quadrado ajustado & 0,5344 & \\
\hline
\end{tabular}

Fonte: Elaboração própria a partir de dados da Inloco (2020) e do IBGE (2011). 
a taxa de isolamento esperada para uma área com renda média abaixo de um salário-mínimo, caso estivesse localizada no centro de Porto Alegre. Os demais coeficientes mostram o aumento no isolamento esperado para cada crescimento de 1 unidade das variáveis. Como as variáveis representam o percentual daquela faixa de renda na região, 1 unidade significa $100 \%$ da área formada por setores censitários daquela faixa. Ou seja, o isolamento estimado para áreas com renda entre 1 e 2 salários-mínimos é de 0,3909+0,0255 = 41,64\%.

A faixa entre 5 e 10 salários-mínimos é a que apresenta o maior isolamento, com 9,59 pontos percentuais acima da base. Além disso, independentemente da renda, a cada quilômetro de afastamento da prefeitura, o isolamento cai 0,12 pontos percentuais. Isso significa que áreas mais afastadas tendem a ter um isolamento menor que áreas centrais, mesmo que estejam na mesma faixa de renda. No entanto, como a renda não é igualmente distribuída no território e a maioria das áreas afastadas é habitada por população de baixa renda, os coeficientes de renda e de distância combinados resultam numa diferença ainda maior de isolamento entre os grupos sociais. 0 modelo também deixou mais explícita a diferença entre as maiores faixas de renda, indicando que, nas regiões habitadas por pessoas com renda acima de 10 salários-mínimos, o distanciamento social está sendo menos respeitado, mesmo que as condições financeiras dessas pessoas permitam o isolamento.

Por fim, é importante ressaltar que o modelo, apesar de significativo, só explica 54\% das variações no isolamento. Há, portanto, outros fatores importantes que influenciam o índice, além da renda e da distância do centro, e que não estão sendo considerados no modelo.
Índice de isolamento social nas regiões do Orçamento Participativo

Para finalizar, foi calculado o isolamento médio nas 17 regiões do Orçamento Participativo (OP) e foi realizada uma comparação com o Índice de Desenvolvimento Humano (IDH) ${ }^{6}$ de cada uma. Os resultados são apresentados na Tabela 4 e na Figura 5.

Apesar de aparecer na Tabela, a região das Ilhas não será considerada na análise. Como fica claro no Gráfico 2, ela possui um padrão completamente diferente das demais. Isso acontece porque, nessa região, a ocupação é pouco densa, dificultando o cálculo da taxa de isolamento, já que não há dados suficientes. Apenas um polígono da região apresentou informações para todos os dias do período analisado, sendo localizado numa área de renda acima da média da região, o que explica o isolamento relativamente alto, apesar do baixo IDH da região como um todo. Portanto, o resultado não reflete a realidade da região. Já as demais regiões tiveram todas, para o cálculo do seu isolamento, o mínimo de 10 polígonos cada uma.

As duas regiões do OP com maior taxa de isolamento são exatamente as duas com maior IDH: Centro e Noroeste. No outro extremo, os menores isolamentos foram encontrados na Restinga e na região Nordeste, ambas com IDH entre os mais baixos da cidade. Considerando as 16 regiões analisadas, a correlação entre o índice de isolamento e o IDH foi de 0,91 , o que mostra que as duas variáveis estão altamente relacionadas.

Apesar dos limites dos dados e da defasagem de usar um censo realizado há uma década, está claro que a distribuição espacial do nível de isolamento em Porto Alegre 
Tabela 4 - Isolamento social e IDH nas regiões do Orçamento Participativo

\begin{tabular}{l|c|c|c|c|c}
\hline \multirow{2}{*}{} & \multirow{2}{*}{ IDH } & \multicolumn{3}{|c}{ Isolamento médio de 7/6 a 24/10/20 } \\
\cline { 3 - 5 } & & $\begin{array}{c}\text { Dias úteis } \\
\%\end{array}$ & $\begin{array}{c}\text { Sábados } \\
\%\end{array}$ & $\begin{array}{c}\text { Domingos e } \\
\text { feriados - \% }\end{array}$ & $\begin{array}{c}\text { Total } \\
\%\end{array}$ \\
\hline 1 - Humaitá-Navegantes & 0,765 & 38,3 & 43,5 & 53,2 & 41,5 \\
\hline 2 - Noroeste & 0,890 & 41,7 & 46,5 & 55,4 & 44,6 \\
\hline 3 - Leste & 0,777 & 39,2 & 44,1 & 53,9 & 42,4 \\
\hline 4 - Lomba do Pinheiro & 0,683 & 38,0 & 43,4 & 53,6 & 41,4 \\
\hline 5 - Norte & 0,729 & 37,3 & 42,5 & 52,6 & 40,6 \\
\hline 6 - Nordeste & 0,638 & 35,6 & 40,6 & 50,2 & 38,7 \\
\hline 7 - Partenon & 0,764 & 39,1 & 44,7 & 53,6 & 42,3 \\
\hline 8 - Restinga & 0,685 & 35,6 & 40,1 & 50,3 & 38,6 \\
\hline 9 - Glória & 0,733 & 36,9 & 43,1 & 54,2 & 40,7 \\
\hline 10 - Cruzeiro & 0,747 & 38,2 & 43,0 & 53,1 & 41,3 \\
\hline 11 - Cristal & 0,809 & 39,7 & 45,2 & 54,2 & 42,9 \\
\hline 12 - Centro Sul & 0,797 & 38,7 & 43,8 & 53,6 & 41,9 \\
\hline 13 - Extremo Sul & 0,714 & 35,9 & 40,8 & 50,9 & 39,1 \\
\hline 14 - Eixo Baltazar & 0,779 & 37,1 & 42,3 & 52,3 & 40,4 \\
\hline 15 - Sul & 0,843 & 39,8 & 44,4 & 54,3 & 42,8 \\
\hline 16 - Centro & 0,935 & 44,6 & 49,0 & 57,7 & 47,4 \\
\hline 17 - Ilhas & 0,659 & $(42,6)$ & $(50,3)$ & $(62,1)$ & $(46,9)$ \\
\hline
\end{tabular}

Fonte dos dados brutos: Inloco (2020) e ObservaPOA (2015).

Figura 5 - Índice de isolamento social nas regiões do Orçamento Participativo (valor médio entre $7 / 6$ e 24/10/2020)

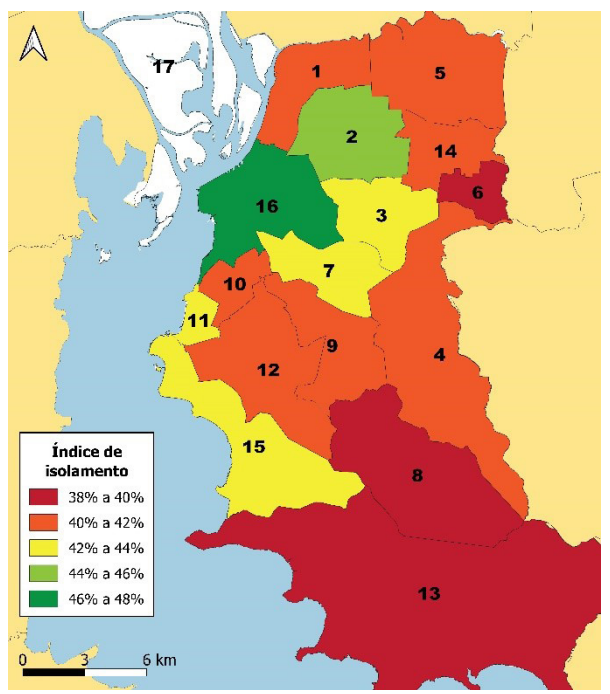

Fonte dos dados brutos: Inloco (2020). 
Gráfico 2 - Isolamento social e IDH nas regiões do Orçamento Participativo

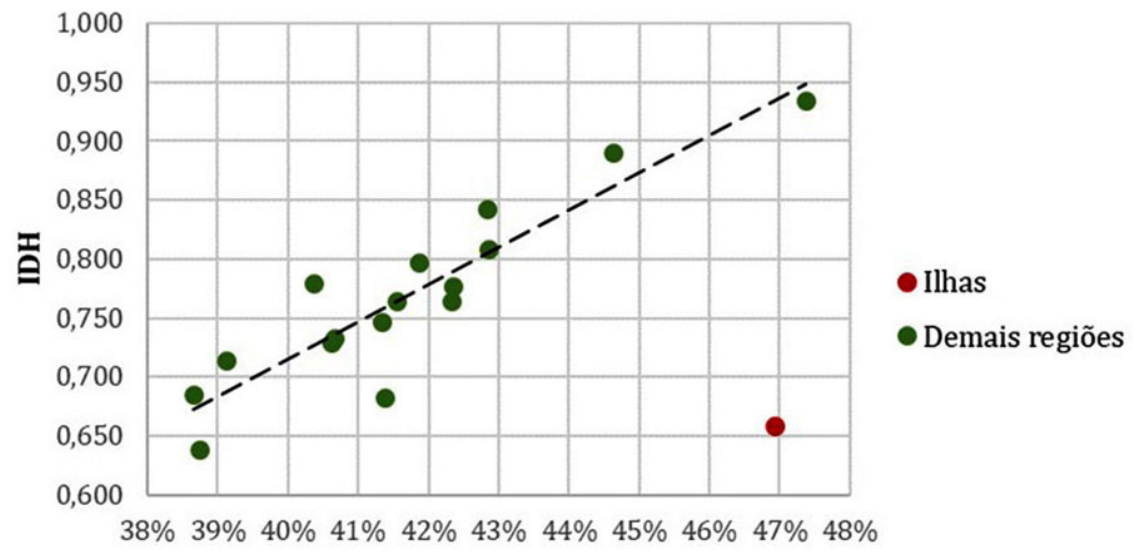

Isolamento

Fonte dos dados brutos: Inloco (2020) e ObservaPOA (2015).

durante a pandemia não é neutra. A possibilidade de exercer o distanciamento recomendado pelas autoridades de saúde está distribuída desigualmente no território, e essa distribuição desigual está relacionada a fatores como trabalho, renda e desenvolvimento de cada região.

\section{Considerações finais}

Uma das grandes polêmicas durante a pandemia que atingiu o mundo em 2020 foi a falsa escolha que deveria ser feita entre "salvar vidas" ou "salvar a economia". Os supostos partidários da economia defendiam que não eram necessárias medidas de distanciamento e que as pessoas deviam voltar ao trabalho. Em geral essa defesa era feita pelo empresariado, que, muitas vezes, não se preocupava em esconder que as vidas em questão não eram as suas. É simbólica a fala do presidente da XP Investimento em 5 de maio de 2020, tentando minimizar a situação da pandemia: "Acompanhando um pouco os nossos números, eu diria que o Brasil está bem. Nossas curvas não estão tão exponenciais ainda, a gente vem conseguindo achatar. [...] 0 pico da doença já passou quando a gente analisa a classe média, classe média alta" (Moura, 2020). Na época, o Brasil já havia registrado cerca de 7 mil mortes. Os meses seguintes mostraram que o pico estava longe de ter passado naquele momento, 
mesmo para o círculo social do presidente da $X P$, mas, olhando para quem teve que sair de casa na reabertura da economia, é possível entender essa posição da classe dominante.

Diversos estudos mostram que nem toda a população brasileira tem o mesmo direito à mobilidade urbana. Dependendo do local de moradia e dos meios de transporte disponíveis, alguns possuem um maior acesso à cidade do que outros. Uma das pesquisas que mostra isso é o Projeto Acesso a Oportunidades, do Ipea, que analisou 20 cidades brasileiras e mostrou que "a população branca e de alta renda tem em média mais acesso a oportunidades de trabalho, saúde e educação do que a população negra e pobre em todas as cidades estudadas" (Pereira et al., 2019). Durante a pandemia, os mesmos grupos que tinham um maior direito à mobilidade passaram a ter um "direito à imobilidade" para se prevenir.

Analisando o caso de Porto Alegre, este artigo mostrou que em toda a cidade foram encontrados níveis de isolamento abaixo do recomendado pelos especialistas para conter a pandemia. No entanto, há diferenças significativas entre as regiões da cidade. A distribuição desigual do isolamento é explicada por fatores como a ocupação, a renda e o desenvolvimento de cada região da cidade.

Muito há de ser explicado sobre essa pandemia. Ainda não estão claros todos os fatores que determinam o grau de contágio e, nos próximos anos, diferentes pesquisas serão necessárias para entender melhor o que está acontecendo. A própria distribuição de casos e óbitos por bairro, que deveria ser uma informação básica para um estudo como esse, não é divulgada de forma clara pelos governos ${ }^{7}$ e merece ser foco de uma pesquisa própria.

Qualquer análise feita durante a ocorrência do fenômeno que está sendo analisado possui limitações. No entanto, há indícios suficientes para acreditar que o distanciamento é um fator relevante para a disseminação do vírus (embora não seja o único), e que as pessoas mais vulneráveis economicamente são as que estão tendo maior exposição ao vírus. Portanto, na falsa dicotomia entre saúde e economia, ambos estão atingindo com mais força os mesmos grupos.

\section{[1] https://orcid.org/0000-0003-3558-802X}

Secretaria de Planejamento, Orçamento e Gestão, Departamento de Economia e Estatística. Porto Alegre, RS/Brasil.

andreaugustin.fee@gmail.com

\section{[II] https://orcid.org/0000-0002-3262-768X}

Universidade Federal do Rio Grande do Sul, Departamento de Geografia, Programa de Pós-Graduação em Geografia. Porto Alegre, RS/Brasil.

paulo.soares@ufrgs.br 


\section{Notas}

(1) O recorte espacial "região" é utilizado, porque uma das divisões oficiais do município de Porto Alegre se dá por "Regiões do Orçamento Participativo", as quais somam 17 regiões. A composição por bairros de cada uma das regiões pode ser consultada em: http://www2. portoalegre.rs.gov.br/op/default.php?reg $=2 \& p \_s e c a o=5$.

(2) Dentro desse período, havia dados para todos os dias, com exceção do dia 29 de junho.

(3) A Inloco não divulgou qual é esse número mínimo.

(4) Com o adiamento do Censo de 2020, devido à pandemia, e com a ameaça de ele não acontecer nem em 2021 por falta de orçamento, restam poucas alternativas para esse tipo de estudo.

(5) Foram considerados dias de chuva aqueles em que a precipitação acumulada entre 7:00 e 22:00 foi de, pelo menos, $1 \mathrm{~mm}$ na estação meteorológica A801, do Instituto Nacional de Meteorologia, localizada no bairro Jardim Botânico.

(6) IDH calculado pelo ObservaPOA (2015), a partir dos dados do Censo 2010.

(7) Na planilha divulgada pela Secretaria Estadual da Saúde, existe o campo "bairro" para cada caso confirmado de covid, mas há vários erros de preenchimento. Apesar de Porto Alegre ter apenas 94 bairros, na planilha aparecem mais de dois mil nomes de bairros. Pior do que os erros de digitação, é a falta de preenchimento: em março de 2021, mês com mais mortes da pandemia, $70 \%$ dos óbitos estavam com o bairro em branco.

\section{Referências}

ANS - Agência Nacional de Saúde Suplementar (2020). Dados e Indicadores do Setor. Disponível em: http://www.ans.gov.br/perfil-do-setor/dados-e-indicadores-do-setor. Acesso em: 27 out 2020.

AQUINO, E. M. L. et al. (2020). Medidas de distanciamento social no controle da pandemia de COVID-19: potenciais impactos e desafios no Brasil. Ciência Saúde Coletiva, v. 25, supl. 1, Rio de Janeiro, jun. Disponível em: https://doi.org/10.1590/1413-81232020256.1.10502020. Acesso em: 27 out 2020.

BRASIL (2019). Ministério da Economia. Boletim mensal sobre os subsídios da União: Deduções do Imposto de Renda Pessoa Física (IRPF) de Despesas Médicas. Edição 9, jul. Disponível em: file:///C:/Users/Andr\%C3\%A9/Desktop/Bibliografia\%20covid/09-bolsubsidios_9_v2.pdf. Acesso em: 27 out 2020.

(2020). Ministério da Saúde. Painel coronavírus. Disponível em: https://covid.saude.gov.br. Acesso em: 25 out 2020. 
CNS - Conselho Nacional de Saúde (2020). Saúde perdeu R\$ 20 bilhões em 2019 por causa da EC 95/2016. 28 fev. Disponível em: https://conselho.saude.gov.br/ultimas-noticias-cns/1044saude-perdeu-r-20-bilhoes-em-2019-por-causa-da-ec-95-2016. Acesso em: 27 out 2020.

DEMENECH, L. M.; DUMITH, S. C.; VIEIRA, M. E. C. D.; NEIVA-SILVA, L. (2020). Desigualdade econômica e risco de infecção e morte por COVID-19 no Brasil. Revista Brasileira de Epidemiologia, v. 23, e200095. Disponível em: https://www.scielo.br/scielo.php?script=sci_arttext\&pid=S1415790X2020000100209. Acesso em: 30 out 2020.

GAO, S. et al. (2020). Association of Mobile Phone Location Data Indications of Travel and Stay-at-Home Mandates With COVID-19 Infection Rates in the US. JAMA Network Open, set., v. 3, n. 9, e2020485. Disponível em: https://jamanetwork.com/journals/jamanetworkopen/fullarticle/2770249. Acesso em: 15 set 2020 .

HARTMANN, M. (2020). Porto Alegre teve aumento de 50\% em novos casos de coronavírus em um dia. Zero Hora, 20 ago. Disponível em: https://gauchazh.clicrbs.com.br/saude/noticia/2020/08/ porto-alegre-teve-aumento-de-50-em-novos-casos-de-coronavirus-em-um-dia-entenda-omotivo-cke3h5bdb00a5013ggb2flsvv.html. Acesso em: 30 out 2020.

HSIANG, S. et al. (2020). The effect of large-scale anti-contagion policies on the COVID-19 pandemic. Nature 584, pp. 262-267 (2020). Disponível em: https://doi.org/10.1038/s41586-020-2404-8. Acesso em: 23 set 2020.

IBGE - Instituto Brasileiro de Geografia e Estatística (2011). Censo Demográfico 2010: Resultados do Universo: Agregados por Setores Censitários. Disponível em: ftp://ftp.ibge.gov.br/Censos/ Censo_Demografico_2010/Resultados_do_Universo/Agregados_por_Setores_Censitarios. Acesso em: 12 set 2010 .

(2020). Pesquisa Nacional por Amostra de Domicílios - PNAD COVID19. Disponível em: https:// www.ibge.gov.br/estatisticas/investigacoes-experimentais/estatisticas-experimentais/27947divulgacao-mensal-pnadcovid2.html. Acesso em: 28 out 2020.

INLOCO (2020). Índice de isolamento social. Dados para o Brasil e unidades da federação Dados para municípios e polígonos cedidos ao Comitê de Dados do Gabinete de Crise para o Enfrentamento da Epidemia Covid-19 do Estado de Rio Grande do Sul. Disponíveis em: https:// mapabrasileirodacovid.inloco.com.br/pt. Acesso em: 25 out 2020.

JOHNS HOPKINS UNIVERSITY (2020). COVID-19 Dashboard by the Center for Systems Science and Engineering (CSSE) at Johns Hopkins University (JHU). Disponível em: https://coronavirus.jhu. edu/map.html. Acesso em: 27 out 2020.

MAMMARELLA, R.; PESSOA, M. L.; FERREIRA, G. S.; TARTARUGA, I. G. P. (2015). “Estrutura social e organização social do território: Região Metropolitana de Porto Alegre - 1980-2010". In: FEDOZZI, L.; SOARES, P. R. R. Porto Alegre: transformações na ordem urbana. Rio de Janeiro, Letra Capital, Observatório das Metrópoles.

MARINO, A.; MENDONÇA, P.; FOLETTO, L.; BRITO, G.; ROLNIK, R.; SANTORO, P. (2020a). Para combater a covid-19, é preciso entender exatamente onde ela está. LabCidade - Laboratório Espaço Público e Direito à Cidade. Disponível em: http://www.labcidade.fau.usp.br/para-combater-a-covid-19e-preciso-entender-exatamente-onde-ela-esta. Acesso em: 25 out 2020. 
MARINO, A.; KLINTOWITZ, D.; BRITO, G.; ROLNIK, R.; SANTORO, P.; MENDONÇA, P. (2020b). Circulação para trabalho explica concentração de casos de Covid-19. LabCidade - Laboratório Espaço Público e Direito à Cidade. Disponível em: http://www.labcidade.fau.usp.br/circulacao-para-trabalhoinclusive-servicos-essenciais-explica-concentracao-de-casos-de-covid-19. Acesso em: 25 out 2020.

MARINO, A. K.; KOMATSU, B. K.; MENEZES-FILHO, N. (2020). Os impactos das medidas de distanciamento social sobre o crescimento do número de casos e óbitos por Covid no Brasil. Insper Policy Paper, n. 49 , set.

MOURA, J. (2020). Pico de Covid-19 nas classes altas já passou; o desafio é que o Brasil tem muita favela, diz presidente da XP. Folha de S.Paulo. 5 maio. Disponível em: https://www1.folha.uol.com.br/ mercado/2020/05/brasil-esta-indo-bem-no-controle-do-coronavirus-e-pico-nas-classes-altasja-passou-diz-presidente-da-xp.shtml. Acesso em: 27 out 2020.

NATIVIDADE, M. S. et al. (2020). Social distancing and living conditions in the pandemic COVID-19 in Salvador-Bahia, Brazil. Ciência \& Saúde Coletiva, v. 25, n. 9, pp. 3385-3392.

OBSERVAPOA - Observatório da Cidade de Porto Alegre (2015). Cinco regiões do OP de Porto Alegre apresentam IDH abaixo da média nacional. Disponível em: http://www.observapoa.com.br/ default.php?reg=379\&p_secao=17. Acesso em: 15 set 2020.

(2017). Mapa do ObservaPOA identifica as áreas de vulnerabilidade da capital. Disponível em: http://observapoa.com.br/default.php?reg=490\&p_secao=17. Acesso em: 23 ago 2020.

PEREIRA, R. H. M.; BRAGA, C. K. V.; SERRA, B.; NADALIN, V. (2019). Desigualdades socioespaciais de acesso a oportunidades nas cidades brasileiras. Texto para Discussão Ipea, 2535. Brasília, Instituto de Pesquisa Econômica Aplicada. Disponível em: http://repositorio.ipea.gov.br/ bitstream/11058/9586/1/td_2535.pdf. Acesso em: 27 out 2020.

PNUD. FPJ. IPEA (2020). Atlas do Desenvolvimento Humano no Brasil. Disponível em: http://www. atlasbrasil.org.br. Acesso em: 20 out 2020.

RIBEIRO, L. C. Q.; RIBEIRO, M. (orgs.) (2016). Índice de Bem-estar Urbano dos municípios Brasileiros. Rio de Janeiro, Observatório das Metrópoles.

RIO GRANDE DO SUL (2020a). Secretaria de Planejamento, Orçamento e Gestão. RS retoma maior índice de isolamento do país. 16 jul. Disponível em: https://planejamento.rs.gov.br/rs-retomamaior-indice-de-isolamento-do-pais. Acesso em: 28 out 2020.

(2020b). Secretaria Estadual da Saúde. Painel Coronavírus RS. Disponível em: https://ti.saude. rs.gov.br/covid19. Acesso em: 25 out. 2020.

SANTOS, M. (2012). Por uma economia política da cidade. São Paulo, Edusp.

SOROEPI MSP (2020). Inquéritos soroepidemiológicos seriados para monitorar a prevalência da infecção por SARS-CoV-2 no Município de São Paulo. Fase 4. Disponível em: https://www. monitoramentocovid19.org/fase-4. Acesso em: 29 out 2020.

UNDP - United Nations Development Programme (2019). Human Development Report 2019: Beyond income, beyond averages, beyond today: Inequalities in human development in the 21st century. Nova York, Organização das Nações Unidas. Disponível em: http://hdr.undp.org/sites/default/ files/hdr2019.pdf. Acesso em: 27 out 2020. 
UNAFISCO - Associação Nacional dos Auditores Fiscais da Receita Federal do Brasil (2020). Imposto sobre grandes fortunas: definição da arrecadação, alíquota e limite de isenção ideais, perfil dos contribuintes, tabela progressiva e recursos para a crise resultante da pandemia da Covid-19. Nota Técnica Unafisco n. 17/2020. Disponível em: https://unafisconacional.org.br/wp-content/ uploads/2020/09/NT-17-1.pdf. Acesso em: 27 out 2020.

ZHOU, Y.; XU, R.; HU, D.; YUE, Y.; LI, Q.; XIA, J. (2020). Effects of human mobility restrictions on the spread of COVID-19 in Shenzhen, China: a modelling study using mobile phone data. Lancet Digital Health, v. 2, n. 8, E417-E424, ago.

Texto recebido em 30/out/2020

Texto aprovado em $9 / \mathrm{abr} / 2021$ 
